\title{
PELESTARIAN DOLANAN ANAK DI DUSUN SIDOREJO DESA SIDOREJO KECAMATAN KRIAN KABUPATEN SIDOARJO
}

Khoirul Ngibad, Ernawati, Anis Putri Ambarwati, Ayu Putri C., M. Ali Zainuddin, Nanda Ady Cahyono Universitas Maarif Hasyim Latif, Indonesia khoirul_ngibad@dosen.umaha.ac.id

\begin{abstract}
Sidorejo backwoods is backwoods located in the $\mathrm{v}$ Sidorejo illage, Krian District, Sidoarjo Regency. The condition of preservation of dolanan anak or traditional games in Sidorejo backwoods is currently very poor. Most children in Sidorejo backwoods are more familiar with modern games, such as: online games, playstation and others. Based on the results of a survey conducted by students of Kuliah Kerja Nyata (KKN) in Sidorejo backwoods, it can be seen that the community of Sidorejo backwoods less responsive to the activity of reviving dolanan anak.. Therefore, the aim of Community Service is to preserve local culture through dolanan anak which is one part of the core program carried out by students of KKN from Universitas Maarif Hasyim Latif in order to preserve the existing local culture. The community service activities that are conceptualized in Kuliah Kerja Nyata $(\mathrm{KKN})$ scheme involved students of Universitas Maarif Hasyim Latif from various study programs guided by Field Supervisors. The implementation of community service begins with initial observations in the field of traditional games among school children from Dusun Sidorejo RW 04 and 05 and then determines the schedule of dolanan anak activities through traditional children's play followed by all children from Dusun Sidorejo RW 04 and 05 . The results of this community service program have made the children more enthusiastic to revive the existing traditional games. The parents do not forbid their children
\end{abstract}


to play traditional games so that it can support the success of programs run by students from Universitas Maarif Hasyim Latif in the village of Sidorejo.

Keywords: Layanan Komunitas, dolanan anak, Permainan Tradisional, Desa Sidorejo

\section{Pendahuluan}

Dusun Sidorejo merupakan sebuah dusun yang berada dalam kawasan desa atau kelurahan Sidorejo Kecamatan Krian Kabupaten Sidoarjo. Asal usul Desa Sidorejo Kecamatan Krian Kabupaten Sidoarjo menurut nara sumber atau sesepuh desa masih belum diketahui dengan jelas. Desa ini sangat strategis letak geografisnya dengan luas tanah + 10.000 Ha. Dengan jumlah penduduk yang sekarang ini mencapai + 10.000 jiwa keseluruhan dari usia 0 - 17 tahun ke atas dengan jumlah wajib E- KTP + 6625 atau usia 17 tahun ke atas. Desa Sidorejo terdiri dari 8 pedukuan/ Dusun dan 4 perumahan dan 1 kavling serta 13 RW dan 73 RT Desa terluas dan paling banyak penduduknya di Kecamatan Krian Kabupaten Sidoarjo. Nama - nama Dusun yang ada di Desa Sidorejo Kecamatan Krian Kabupaten Sidoarjo, antara lain: Dusun Bendomungal/ Pondok Darul Falah, Dusun Bareng, Dusun Sidorejo, Dusun Sidorame, Dusun Semampir, Dusun Madubronto, Dusun Sidorenggo. 
Di era ini, dampak negatif dari adanya teknologi menyebabkan permasalahan-permasalahan pada generasi penerus bangsa ini. Dengan adanya teknologi, berbagai macam budaya asing dapat masuk ke dalam budaya kita. ${ }^{1}$ Salah satu budaya bangsa kita adalah adanya permainan tradisional yang diwariskan oleh nenek moyang kita. Akan tetapi, dengan adanya permainan modern yang berbasis digital, permainan tradisional bangsa ini mulai dilupakan. Padahal dolanan anak atau permainan tradisional tersebut dapat membentuk karakter dan budi pekerti anak-anak. Selain itu, nilai-nilai yang terkandung dalam permainan tradisional, sperti: kebersamaan, kearifan, kerjasama, dan lain-lain sangat penting untuk mendukung Pendidikan karakter generasi penerus bangsa ini.

Kondisi dolanan anak atau permainan tradisional di Dusun Sidorejo saat ini sangat memprihatinkan. Kebanyakan anak-anak di Dusun Sidorejo lebih mengenal permainan modern, seperti game online, playstation dan lainnya. Beberapa hal yang menjadi faktor penyebab, di antaranya: munculnya permainan-permainan baru yang beraneka ragam dalam bentuk barang elektronik atau yang tersedia dalam smartphone. Permainan-permainan modern tersebut lebih mudah

${ }^{1}$ S. Handayani. Sifat kimia entisol pada sistem pertanian organik. Jurnal Ilmu Pertanian, (2003), 63-69. 
diakses oleh anak-anak yang mempunyai smartphone dan akses internet. Selain itu, faktor kelalaian orang tua untuk mewariskan atau melestarikan budaya-budaya atau permainan tradisional ke anakanaknya.

Nama-nama permainan tradisional atau dolanan anak yang harus dilestarikan, meliputi: congklak atau dakon, engrang, lompat tali, bola bekel dan lain sebagainya. Permainan dakon dimainkan oleh 2 orang dengan menggunakan media papan dan biji sawo atau kerikil. Permainan congklak ini sangat familiar di Pulua Jawa dan di luar Pulau Jawa. Permainan egrang membutuhkan 1 pasang batang bambu yang ditambah dengan pijakan kaki. Permainan egrang sangat memerlukuan adanya keseimbangan dan kecepatan melangkah dari para pemain. Pemenang dalam permainan egrang adalah pemain yang paling cepat sampai ke garis finish. Di sisi lain, permainan lompat tali menggunakan alat tali yang biasanya dapat dibuat secara tradisional dari karet gelang. Sistem permainannya adalah ada 2 pemain yang mengayunkan tali dan ada pemain-pemain yang melakukan gerakan mengangkat tubuh dari suatu titik ke titik lain yang lebih jauh atau tinggi. Pemain akan kalah jika bagian tubuh pemain mengenai tali yang diayunkan.

Berdasarkan hasil survei yang dilakukan pada saat kegiatan KKN di Dusun Sidorejo, penulis dapat menyimpulkan bahwa masyarakat

Vol. 2 No. 1 , A pril 2020
Khoirul Ngibad, Dkk| 88

gurnal Pengabdian Masyarakat 
Dusun Sidorejo kurang responsif terhadap kegiatan menghidupkan kembali dolanan anak. Hal ini disebabkan karena kebanyakan masyarakat di Dusun Sidorejo adalah pekerja, sehingga sepulang bekerja mereka lebih memilih untuk beristirahat daripada melakukan kegiatan lain. Oleh karena itu, dalam Pengabdian kepada Masyarakat ini kami mencoba melestarikan budaya lokal melalui dolanan anak yang merupakan salah satu bagian dari program inti yang dilakukan oleh mahasiswa kuliah kerja nyata (KKN) Universitas Maarif Hasyim Latif (UMAHA) Sidoarjo guna melestarikan budaya lokal yang ada. Diharapkan dari pengabdian ini, dapat berkontribusi dalam bidang kebudayaan baik lokal maupun nasional.

\section{Metode Pelaksanaan}

Kegiatan pengabdian kepada masyarakat (PkM) yang terkonsep dalam skema Program Kuliah Kerja Nyata (KKN) ini melibatkan mahasiswa Universitas Maarif Hasyim Latif dari berbagai program studi yang dibimbing oleh Dosen Pembimbing Lapangan (DPL). PkM ini merupakan transfer IPTEKS dengan sosialisasi dan pelatihan serta pembinaan tentang DOLANAN ANAK dalam rangka melestarikan permainan tradisional anak di Dusun Sidorejo RW 04 dan 05 Desa Sidorejo Kecamatan Krian Kabupaten Sidoarjo.

Mitra dalam PkM adalah anak-anak di Dusun Sidorejo RW 04 dan 
05 yang dalam pelaksanaan program ikut aktif dalam kegiatan DOLANAN ANAK. Pelaksanaan PkM ini diawali dengan observasi awal di lapangan tentang permainan tradisional di kalangan anak-anak sekolah dari Dusun Sidorejo RW 04 dan 05 kemudian menentukan jadwal kegiatan DOLANAN ANAK melalui permainan tradisional anak yang diikuti oleh semua anak-anak dari Dusun Sidorejo RW 04 dan 05. PkM ini dilaksanakan selama 1 bulan penuh dimulai pada tanggal 01 Agustus 2019 hingga tanggal 31 Agustus 2019.

Adapun langkah-langkah dalam PkM DOLANAN ANAK di Dusun Sidorejo adalah sebagai berikut :

1. Mengumpulkan anak-anak di suatu lahan yang cukup di balai desa atau di lahan kosong dekat masjid Sidorejo untuk digunakan bermain bersama.

2. Membagi anak-anak ke dalam beberapa kelompok sesuai dengan jenis permainan yang akan dimainkan, yang meliputi: lompat tali, engrang, dakon dan bola bekel. Tentunya di setiap kelompok tersebut terdapat mahasiswa KKN UMAHA sebagai pembimbingnya untuk menjelaskan atau memberi arahan tentang tata cara dari setiap jenis permainan yang ada.

3. Setelah mahasiswa KKN UMAHA memberikan arahan, mahasiswa KKN UMAHA mengajak anak-anak untuk bermain bersama. 
4. Untuk waktu bermainnya pun beragam. Permainan engrang dimainkan pada pagi hari di lapangan balai desa dan malam hari di lapangan dekat masjid dan permainan bola bekel dan dakon dimainkan pada malam hari ketika anak-anak selesai kegiatan bimbel serta permainan lompat tali dimainkan pada pagi hari dan malam hari.

\section{Hasil Dan Pembahasan}

Dalam upaya pelestarian DOLANAN ANAK di Dusun Sidorejo, maka tim PkM mencoba untuk menghidupkan kembali dan mengenalkan secara langsung beberapa dolanan anak tradisional kepada anak-anak di Dusun Sidorejo. Adapun permainan-permainan yang dikenalkan kepada mereka antara lain :

\section{Congklak atau Dakon}

Adapun kegiatan pengenalan permainan congklak atau dakon di Dusun Sidorejo dilakukan dengan cara mengumpulkan anak-anak kecil di depan teras rumah salah satu warga dan menjelaskan terlebih dahulu bagaimana cara bermainnya. Kegiatan tersebut dilakukan oleh mahasiswa KKN pada malam hari setelah kegiatan belajar mengaji. Gambar 1 menampilkan tentang aktivitas mahasiswa KKN yang sedang bermain congklak atau dakon dengan anak-anak kecil di teras rumah salah satu warga Sidorejo. 

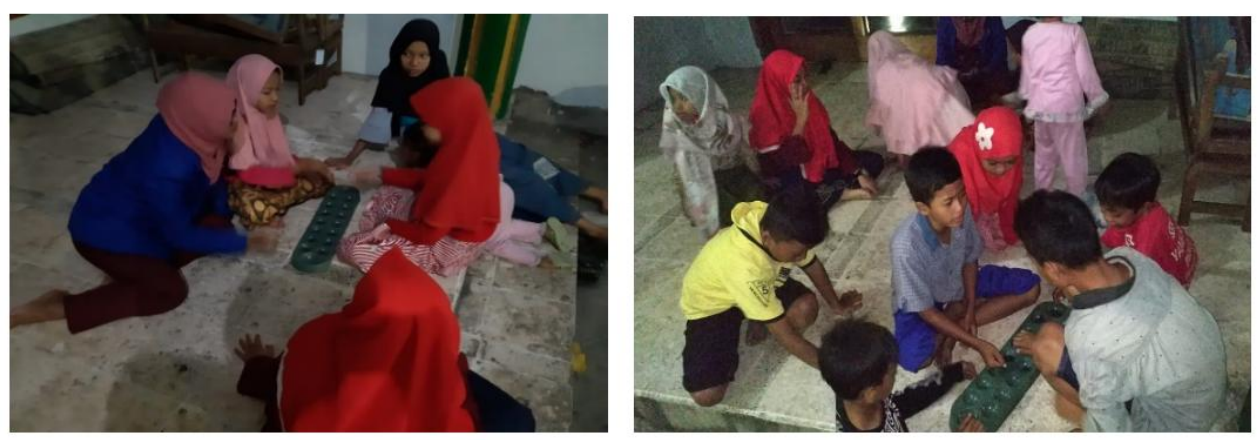

Gambar 1. Mahasiswa KKN bermain congklak atau dakon dengan anak-anak kecil di teras rumah salah satu warga Sidorejo

Permainan congklak tersebut mengandung unsur pendidikan yangkaya akan nilai-nilai karakter. Permainan congkak merupakan permainan anak dari zaman dahulu yang memberi nilai pendidikan bagi anak-anak kampung. Misalnya, permainan ini mengajarkan nilai kejujuran karena ketika pemain menyimpan batu ke dalam lobang yang berisi batu. Orang lain atau lawan main tidak melihat jumlah batu yang digenggam, tidak melihat apakah benar-benar menjatuhkannya ke dalam lubang yang berisi batu atau pura-pura saja. Hal tersebut akan mencegah prilaku curang, mencuri atau korupsi. Selain itu, permainan tersebut juga mengajarkan kepada anak bagaimana taat dan patuh akan aturan, aturan permainan yang dijalankan, tidak ada yang membantah, dan aturan ini disepakati bersama, serta membiasakan untuk sabar menunggu giliran dan melatih berhitung dan belajar berusaha 
semaksimal mungkin.

\section{Engrang}

Permainan tradisional egrang bertujuan untuk mengadu bambu masing-masing pemain. Pertama, memilih pemain 2 lawan saja dengan berkesepakatan terlebih dahulu dan pemain berdiri berhadapan. Pada saat penjaga sudah mulai aba-abanya pemain baru bisa memulai permainan. Setelah penjaga sudah mulai aba-abanya, permainan dimulai dan pemain yang menjatuhkan lawannya dinyatakan menang dalam permianan Egrang. Permainan ini memiliki nilai yang baik dalam budaya, nilai kerja kelas dan sportivitas dalam bermain.

Untuk jenis permainan engrang ini, mahasiswa KKN UMAHA melakukan kegiatan dari nol. Yaitu memulai dari pembuatan engrang itu sendiri sampai pelaksanaan. Mahasiswa KKN mensosialisasikan ke anak-anak yang ada di Dusun Sidorejo tentang permainan engrang. Gambar 2 merupakan proses pembuatan engrang oleh mahasiswa KKN UMAHA dan Gambar 3 memperlihatkan mengenai mahasiswa KKN UMAHA yang sedang mengajarkan cara bermain engrang kepada anakanak kecil yang ada di dusun Sidorejo 


\begin{tabular}{|lll}
\hline ISSN & $: 2656-5161$ \\
e-ISSN & $: 2686-0643$
\end{tabular}
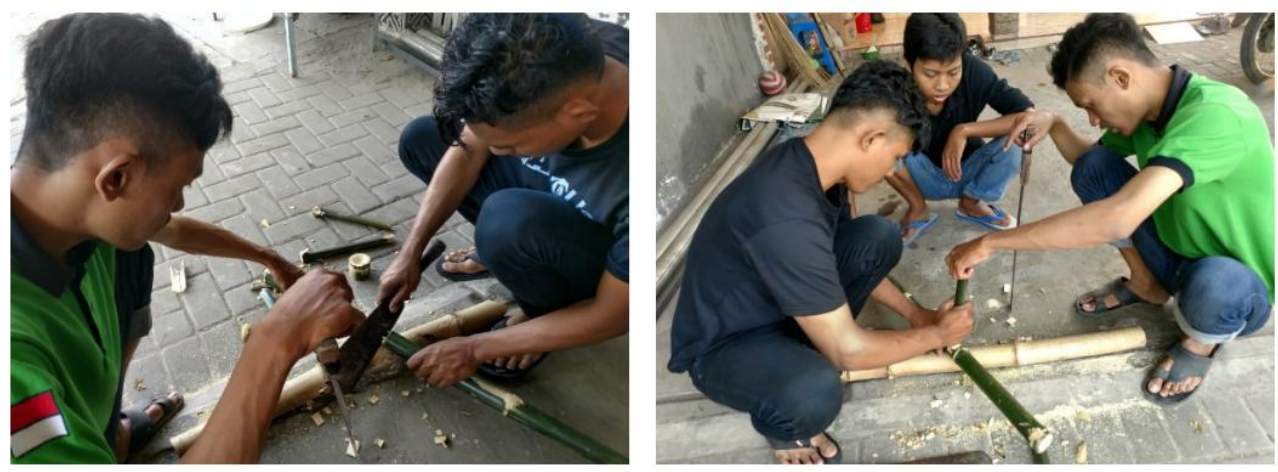

Gambar 2. Proses pembuatan engrang oleh mahasiswa KKN UMAHA
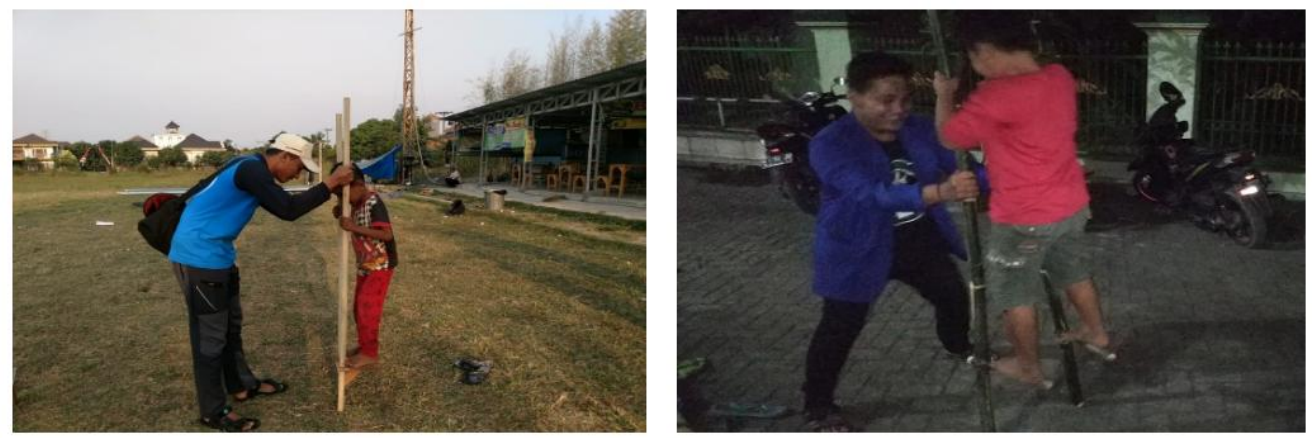

Gambar 3. Mahasiswa KKN UMAHA mengajarkan cara bermain engrang kepada anak-anak kecil yang ada di dusun Sidorejo

\section{Lompat Tali}

Kegiatan pengenalan dan pelestarian permainan lompat tali di Dusun Sidorejo dilakukan dengan cara mengumpulkan anak-anak kecil di depan teras rumah. Anak-anak diajari terlebih dahulu tentang cara bermain lompat tali. Permainan lompat tali mengajarkan anak-anak

Vol. 2 No. 1, April 2020
Khoirul Ngibad, Dkk| 94 gurnal Pengabdian Masyarakat 
tentang nilai kerja keras, ketangkasan, kecermatan dan sportivitas. Kerja keras dari seorang anak akan terlihat dari semangat para pemain yang berusaha supaya bisa melompati tali dengan beraneka macam ketinggian dan bentuk lompatan. Ketangkasan dan kecermatan dari seorang anak juga akan tercermin dari usaha pemain untuk melakukan perkiraan antara ketinggian tali dengan lompatan sedangkan sportivitas anak akan tercermin dari sikap pemain yang tidak melakukan tindakan curang dan bersedia menggantikan sebagai pemegang dan pengayun tali apabila anak melekukan pelanggaran terhadap peraturan yang telah disepakati bersama. Gambar 4 menunjukkan tentang aktivitas mahasiswa KKN UMAHA bdalam bermain lompat tali bersama dengan anak-anak di dusun Sidorejo
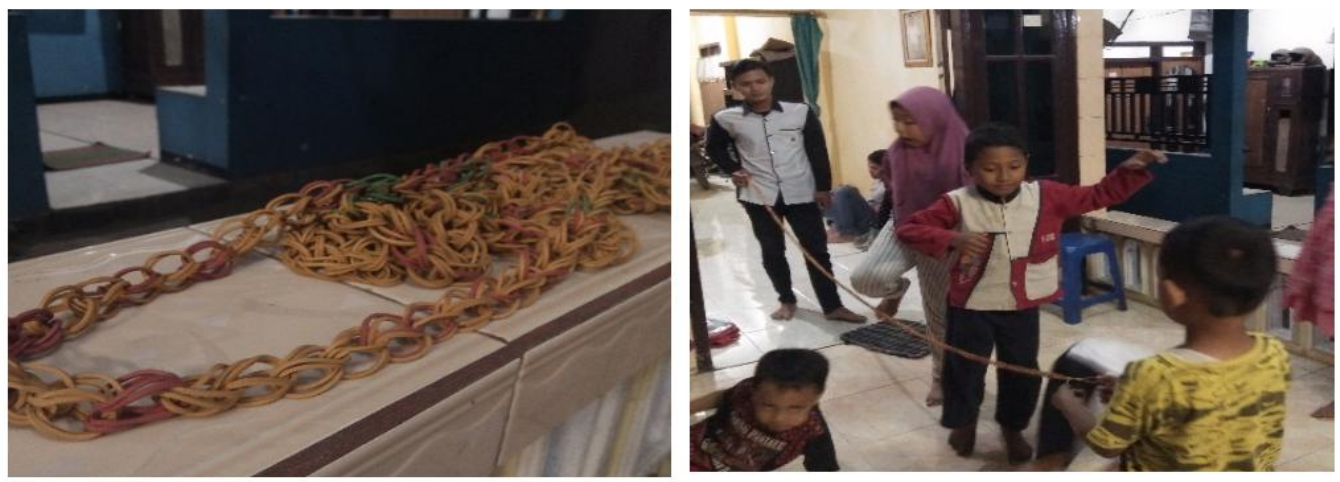

Gambar 4. Mahasiswa KKN UMAHA bermain lompat tali bersama dengan anak-anak di dusun Sidorejo

Vol. $2 \mathrm{No.} 1$, A p ril 2020
Khoirul Ngibad, Dkk| 95

gurnal Pengabdian Masyarakat 


\section{Bola Bekel}

Permainan bola bengkel ini melatih ketangkasan dan daya nalar anak dalam mengambil bola bekel secara cepat dan tepat. Dalam memainkannya juga membutuhkan kesabaran dalam bertindak sehingga menciptakan sesuatu yang positif, seperti tidak gegabah dalam mengambil keputusan. Gambar 5 merupakan aktivtas mahasiswa KKN UMAHA dalam bermain bola bekel bersama dengan anak-anak di Dusun Sidorejo
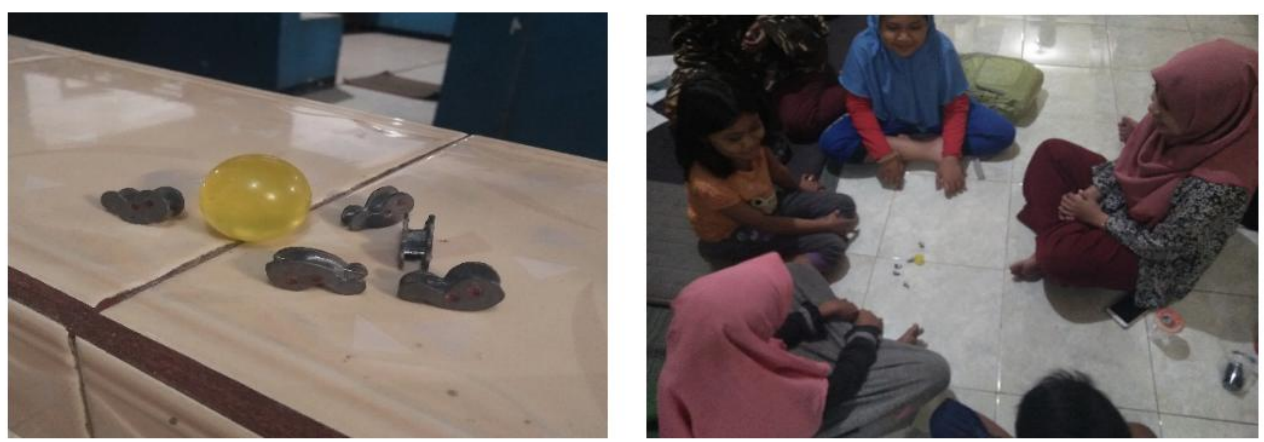

Gambar 5. Mahasiswa KKN UMAHA bermain bola bekel bersama dengan anak-anak di Dusun Sidorejo

Dari setiap permainan yang sudah dijalankan diatas, pastinya memiliki makna yang tersirat. Adapun makna tersirat tersebut adalah budi pekerti, kebersamaan, dan komunikasi sosial. Seperti dalam permainan bola bekel dan congklak, dari permainan tersebut anak-anak diajarkan untuk bersabar menunggu giliran bermain. Mereka 
diharuskan memiliki budi pekerti yang baik yaitu dengan sifat sabar dan tidak mengganggu temannya saat sedang bermain. Untuk makna kebersamaan dan komunikasi sosial sendiri, tentu di setiap permainan sudah mengandung makna tersebut. Setiap permainan yang ada juga mengandung unsur olahraga sehingga anak-anak bisa bermain sambil olahraga.

\section{Kesimpulan}

Program pengabdian kepada masyarakat dalam pelestarian dolanan anak atau permainan tradisional yang dijalankan oleh mahasiswa UMAHA selama KKN di dusun Sidorejo membuat anakanak semakin semangat dan antusias untuk menghidupkan kembali dolanan anak yang ada. Respon orang tua terhadap dolanan anak di dusun Sidorejo masih kurang antusias, hal itu dikarenakan kebanyakan dari mereka adalah para pekerja sehingga mereka lebih memilih istirahat jika memiliki waktu luang daripada harus melakukan kegiatan lain. Namun sisi positifnya adalah para orang tua tidak melarang anaknya untuk bermain permainan tradsional, sehingga hal itu dapat menunjang keberhasilan program yang dijalankan oleh mahasiswa KKN UMAHA di dusun Sidorejo.

\section{Daftar Pustaka}

Handayani, T. Upaya menghidupkan kembali dolanan anak-anak sebagai mdia 
pelestarian budaya. Yogyakarta: Sarasehan Menggali Nilai-Nilai Kebangkitan nasional, 2003.

Pathurohman, M., \& Wibowo, R. Meningkatkan Hasil Belajar Lompat melalui Aktivitas Lompat Tali dengan Penerapan Gaya Practise. Jurnal Pendidikan Jasmani Dan Olahraga, 2017.

Prayitno, L. L. Permainan" Congklak" Untuk Mengajarkan Operasi Penjumlahan di Sekolah Dasar. Buana Pendidikan: Jurnal Fakultas Keguruan dan Ilmu Pendidikan, 2014.

Yenti, N. P., \& Nurizzati, N. Kemas Ulang Informasi Permainan Tradisional Minangkabau di Kabupaten Pesisir Selatan. Ilmu Informasi Perpustakaan dan Kearsipan, 2018. 